\title{
Comparison of cumulative and non-cumulative techniques to measure dose-response curves for beta agonists in patients with asthma
}

\author{
JOHN BRITTON, ANNE TATTERSFIELD
}

From the Faculty of Medicine, Southampton General Hospital, Southampton

ABSTRACT It has been suggested that the use of a cumulative technique to obtain bronchodilator dose-response curves will cause a greater response than a non-cumulative technique, because sequential doses of drug will penetrate further into the lung. To test this hypothesis we have compared cumulative and non-cumulative dose-response curves for inhaled isoprenaline in 10 subjects with stable asthma, measuring $\mathrm{FEV}_{1}$, forced vital capacity (FVC), and peak expiratory flow rate (PEFR). With both techniques there was an increased response with increasing doses of isoprenaline for all the dose-response curves except for the non-cumulative PEFR response, which reached a plateau with the $20 \mu \mathrm{g}$ dose. The area under the dose-response curve for FEV 1 was significantly greater after cumulative administration of isoprenaline than with the noncumulative technique. The increase in FVC and PEFR tended to be greater with the cumulative technique but the differences were not significant. This study confirms that the airway response to an inhaled $\beta$ agonist may be greater when a cumulative inhalation technique is used.

When Williams and Kane' ${ }^{1}$ administered inhaled isoprenaline to asthmatic patients by a noncumulative technique, they found that the response reached a plateau after the $20 \mu \mathrm{g}$ dose. In contrast, Shenfield and Paterson, ${ }^{2}$ using a cumulative technique to administer $\beta$ agonists, found a dose related increase in $\mathrm{FEV}_{1}$ and a linear log dose-response relationship. Williams and $\mathrm{Kane}^{1}$ suggested that the increasing response with increasing doses with the cumulative technique might be due to increased penetration of sequential doses of inhaled drug after the bronchodilatation caused by early doses. Since there has been no direct comparison of cumulative and non-cumulative techniques we have compared dose-response curves for inhaled isoprenaline given by the two techniques in subjects with stable asthma. Isoprenaline was chosen to allow direct comparison of our results with those of Williams and Kane. ${ }^{1}$

Address for reprint requests: Professor AE Tattersfield, Respiratory Medicine Unit, City Hospital, Nottingham NG5 1PD.

Accepted 2 April 1984

\section{Methods}

Ten patients (six of them men), aged 22-66 years, with asthma were selected on the basis of stable spirometric performance at clinic attendance over the past year and pretreatment $\mathrm{FEV}_{1}$ values of $20-70 \%$ of either the predicted normal value or their previous best, whichever was greater. All had demonstrated an improvement in $\mathrm{FEV}_{1}$ of at least $20 \%$ after inhaling $200 \mu \mathrm{g}$ salbutamol and were experienced in the use of metered dose aerosols, spirometry, and peak flow measurements. Patients with a history of heart disease and those taking regular long acting oral bronchodilators were excluded. Patients having regular prednisolone were included if the dose had been unchanged for more than six weeks. Regular medication included inhaled salbutamol (9 patients), inhaled isoprenaline (1), inhaled beclomethasone (8), sodium cromoglycate (1), ipratropium bromide (1), and oral prednisone (4). Approval for the study was obtained from the Southampton Ethical Committee and all patients gave informed consent before taking part.

Each patient attended on five days at the same time, having abstained from bronchodilator treat- 

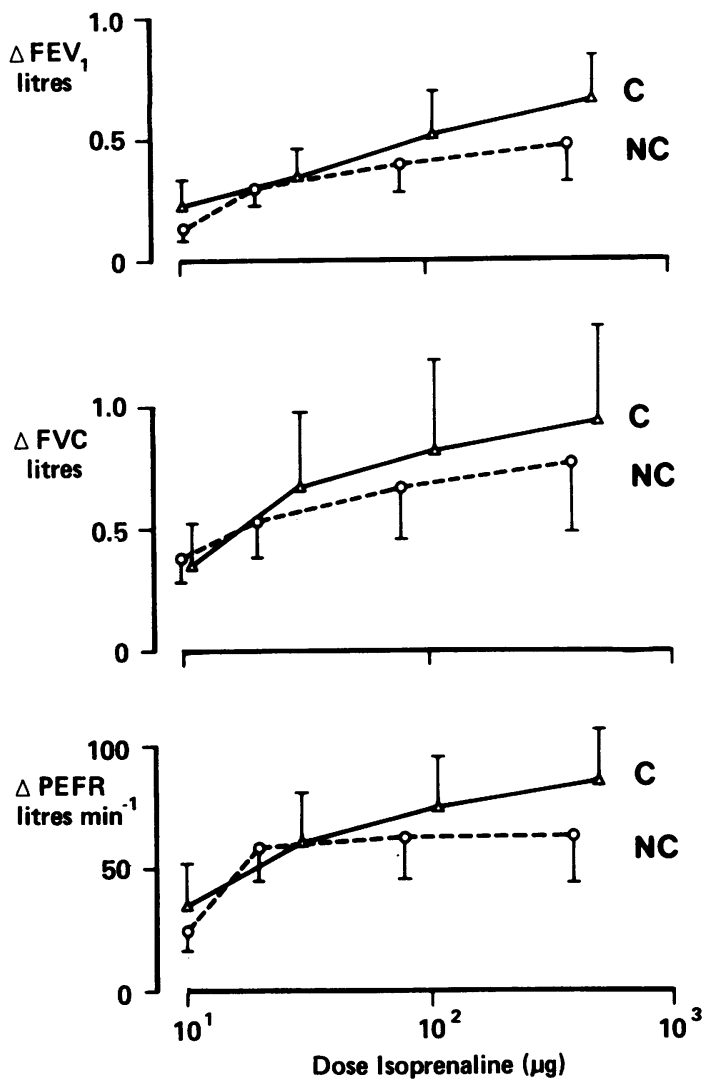

Mean change in $F E V_{p}$ forced vital capacity $(F V C)$, peak expiratory flow rate $(P E F R)(+1 S E)$ with increasing doses of isoprenaline for the cumulative $(C)$ and non-cumulative (NC) techniques.

ment for at least six hours. After a 10 minute rest $\mathrm{FEV}_{1}$, forced vital capacity (FVC), and peak expiratory flow rate (PEFR) were measured and the best of three measurements taken.

The sequence of the five studies was randomised. On four of the visits a single inhalation of isoprenaline, $10,20,80$, and $400 \mu \mathrm{g}$, was given from specially prepared metered dose inhalers in a double blind manner. FEV, FVC, and PEFR were measured five minutes later. On the fifth visit the same four doses were administered cumulatively in ascending order of magnitude at five minute intervals in a single blind manner. FEV,$F V C$, and PEFR were measured five minutes after each dose.

When the study was complete, baseline FEV readings were compared to determine whether any value differed by more than $15 \%$ from the collective mean for that subject. If it did that particular study was then repeated. This was necessary in two subjects only.
ANALYSIS OF RESULTS

Mean baseline values for FEV, FVC, and PEFR on the different study days were compared by Student's $t$ test. The area under the dose-response curves for each subject was estimated by trapezoidal integration. Comparability of dose-response curves was achieved by interpolation of a cumulative $400 \mu \mathrm{g}$ response. Mean values were compared by paired $t$ test.

\section{Results}

Mean baseline values of $\mathrm{FEV}_{1}$ for the 10 subjects ranged from 0.49 to 2.08 (21-60\% predicted). The maximum percentage change in $\mathrm{FEV}_{1}$ from baseline after isoprenaline ranged from $30 \%$ to $178 \%$.

Mean baseline values for the cumulative doseresponse studies were 1.18 and 2.29 for $F E V_{1}$ and FVC and $210 \mathrm{l} \mathrm{min}^{-1}$ for PEFR. These did not differ from the mean baseline values on the four noncumulative study days.

Mean values for the change in $\mathrm{FEV}_{1}, \mathrm{FVC}$, and PEFR are shown in the figure. The area under the cumulative $\mathrm{FEV}_{1}$ dose-response curve was greater than that under the non-cumulative curve $(p<$ 0.05 ). There was no significant difference between the cumulative and non-cumulative studies for FVC or PEFR. Analysis of the percentage rather than absolute change in the three measurements produced similar curves and identical levels of significance between the two studies.

\section{Discussion}

This is the first direct comparison of cumulative and non-cumulative dose-response curves for the same subjects. Doses of isoprenaline were given at five minute intervals since the response to inhaled isoprenaline is near maximum at this time and a longer time would have rendered earlier doses inactive by the end of the study. ${ }^{3}$

The response was greater with the cumulative technique than the non-cumulative technique for FEV, FVC, and PEFR, though the differences were significant only for $F E V_{1}$. Since the magnitude of the difference between the two techniques was similar for $\mathrm{FEV}_{1}, \mathrm{FVC}$, and PEFR-15\%, 9\%, and $16 \%$ respectively-differences in statistical significance presumably reflect the relatively small differences between the two techniques and the better reproducibility of FEV $\mathrm{F}_{1}$ measurements.

$\mathrm{FEV}_{1}$ and FVC increased with log dose isoprenaline in both the cumulative and the noncumulative studies. Although there was no significant difference between the PEFR doseresponse curves for the two techniques the response 
did reach a plateau at $20 \mu \mathrm{g}$ with the noncumulative technique, as shown previously by Williams and Kane.' The reason for this apparent difference between PEFR and the other measures for the non-cumulative technique only is not clear.

Several studies over the last $\mathbf{3 0}$ years have noted increased bronchodilatation with sequential doses of $\beta$ agonists. ${ }^{4-6}$ Patients with airflow obstruction show more central and less peripheral deposition of radiolabelled aerosol than normal subjects.' It has been suggested that bronchodilatation of airways after the initial doses with a cumulative technique will allow increased penetration of succeeding doses, and our results are consistent with this suggestion. Part of the increased response with the cumulative technique may be due to the delayed effect of early doses but this is likely to be small in view of the known time course of bronchodilatation produced by isoprenaline. In a previous study, where three sequential doses of orciprenaline over 20 minutes caused a greater response than the same total dose given as a single inhalation, the difference was maintained at one hour. ${ }^{5}$

We do not believe that our findings invalidate either the cumulative or the non-cumulative technique, as has been suggested; but they mean that the two techniques cannot be compared directly. In most studies the same technique is used throughout and the cumulative technique has the big advantage of convenience. The results also suggest that small doses of $\beta$ agonists administered at intervals to allow time for bronchodilatation may be as effective as or more effective than a large single dose.

We thank Riker Laboratories for the isoprenaline inhalers, Dr D Machin for statistical advice, and Mrs $M$ Dowling for typing the manuscript.

\section{References}

1 Williams MH, Kane C. Dose-response of patients with asthma to inhaled isoproterenol. Am Rev Respir Dis 1975;111:321-4.

${ }^{2}$ Shenfield GM, Paterson JW. Clinical assessment of bronchodilator drugs delivered by aerosol. Thorax 1973;28:124-8.

${ }^{3}$ Freedman BF, Meisner P, Hill GB. A comparison of actions of different bronchodilators in asthma. Thorax 1968;23:590-7.

${ }^{4}$ Mushin GJ. Time factor in the measurement of response to bronchodilators. Thorax 1967;22:538-42.

${ }^{5}$ Heimer D, Shin C, Williams MH. The effect of sequential inhalations of metaproterenol in asthma. J Allergy Clin Immunol 1980;66:75-7.

- Ullah MI, Newman GB, Saunders KB. Influence of age on response to ipratropium and salbutamol in asthma. Thorax 1981;36:523-9.

${ }^{7}$ Agnew JE, Pavia D, Clarke SW. Airways penetration of inhaled radioaerosol: an index to small airways function. Eur J Respir Dis 1981;62:239-55. 